\title{
Anestesi Scalp Block dan Occipital Block pada Tindakan External Ventricular Drainage (EVD) pada Kehamilan 32 Minggu
}

\author{
Muhammad Arshad"), Dewi Yulianti Bisri**), Sri Rahardjo***) \\ ${ }^{*}$ Departemen Anestesiologi dan Terapi Intensif Fakultas Kedokteran Universitas Sumatera Utara-Rumah Sakit \\ Adam Malik Medan, ${ }^{* *}$ Departemen Anestesiologi dan Terapi Intensif Fakultas Universitas Padjadjaran-RSUP \\ Dr.Hasan Sadikin Bandung, ${ }^{* * *}$ Departemen Anestesiologi dan Terapi Intensif Fakultas Kedokteran Universitas \\ Gadjah Mada-RSUP Dr.Sardjito Yogyakarta
}

\begin{abstract}
Abstrak
Hidrosefalus adalah pembesaran ventrikel otak sebagai akibat peningkatan jumlah cairan serebrospinal (CSS) yang disebabkan oleh ketidakseimbangan antara produksi, sirkulasi dan absorbsinya. Perkiraan wanita hamil yang dilakukan operasi non obstetric sekitar 1-2\%. Pasien obstetri dengan penyakit bedah saraf selalu dirawat di ICU. Insidensi operasi selama kehamilan dilaporkan $42 \%$ prosedur pembedahan terjadi pada trimester pertama, 35\% pada trimester kedua, dan 23\% pada trimester ketiga. Seorang wanita 35 tahun dengan usia kehamilan 32-33 minggu datang ke IGD dengan penurunan kesadaran tanpa riwayat trauma, tidak dijumpai tekanan darah tinggi. Dari pemeriksaan CT-Scan ditemukan adanya hidrosefalus, sehingga dilakukan tindakan external ventricular drainage (EVD). Anestesi untuk pasien dalam keadaan hamil harus mempertimbangkan bayi dalam kandungan sehingga dilakukan pembiusan scalp block dan occipital block. Obat yang digunakan ropivakain $\mathrm{HCl}$ 0,375 \% (sebanyak $10 \mathrm{cc}$ ). Setelah operasi pasien dirawat di ruang pemulihan, 2 jam kemudian dirawat di ruang high care unit (HCU). Pencegahan terhadap hipoksia dan hipotensi adalah keharusan, walaupun periode hipoksemia yang pendek masih bisa ditoleransi. Hipoksemia maternal yang berkepanjangan akan menyebabkan vasokonstriksi sirkulasi uteroplasental yang pada akhirnya menurunkan perfusi sehingga menyebabkan hipoksemia, asidosis dan kematian janin
\end{abstract}

Kata kunci: external ventrikular drainase, hidrosefalus, occipital block, scalp block

JNI 2020, 9 (2): 102-07

\section{Scalp Block and Occipital Block Anesthesia for External Ventricular Drainage (EVD) in 32-Week Pregnancy}

\begin{abstract}
Hydrocephalus is enlargement of the brain ventricles as a result of an increase in the amount of cerebrospinal fluid (CSS) caused by an imbalance between production, circulation and absorption. Estimates of pregnant women in non-obstetric surgery are around $1-2 \%$. Obstetric patients with neurosurgery disorders are always treated in the ICU. The incidence of surgery during pregnancy was reported in $42 \%$ of surgical procedures occurred in the first trimester, $35 \%$ in the second trimester, and $23 \%$ in the third trimester. A 35-year-old woman with 32-33 weeks' gestation came to the emergency room with decreased consciousness yet no history of trauma and high blood pressure. Hydrocephalus were found in CT scan, and the external ventricular drainage (EVD) is taken. The patient has intrauterine pregnancy so the anesthesia choice is scalp block and occipital block. Ropivacaine $\mathrm{HCl} 0.375 \%$ (as much 10cc) was used. After surgery the patient was treated in the recovery room for 2 hours, and discharged to the high care unit (HCU) afterwards. Hypoxia and hypotension is a challenge in short periods of hypoxemia that can still be tolerated. Prolonged maternal hypoxemia prevention will cause uteroplacental circulation vasoconstriction which ultimately reduces perfusion, causing foetal hypoxemia, acidosis and death.
\end{abstract}

Key words: external ventricular drainage, hydrocephalus, occipital block, scalp block

JNI 2020, 9 (2): 102-07

This article is licensed under a

Creative Commons Attribution-NonCommercial-ShareAlike 4.0 International License. CMuhammad Arshad, Dewi Yulianti B, Sri rahardjo (2020)

under the CC-BY-NC-SA license 


\section{Pendahuluan}

Pembedahan non-obstetrik pada pasien hamil merupakan tantangan baru bagi dokter anestesi. Diperkirkaan wanita hamil menjalani operasi non obstetrik sekitar 1-2\%. Pasien obstetrik dengan penyakit bedah saraf selalu dirawat di ICU. ${ }^{1}$ Sekitar $0,75 \%-2 \%$ pembedahan non obstetrik dilakukan selama masa kehamilan. Di Amerika Serikat, diperkirakan sekitar 75.000 wanita hamil menjalani anestesi dan pembedahan setiap tahunnya. Sekitar $42 \%$ prosedur pembedahan terjadi pada trimester pertama, $35 \%$ pada trimester kedua, dan $23 \%$ pada trimester ketiga. Di Swedia, dilaporkan sekitar $42 \%$ prosedur pembedahan terjadi pada trimester pertama, $35 \%$ pada trimester kedua, dan $23 \%$ pada trimester ketiga. Laparoskopi merupakan prosedur pembedahan terbanyak yang dikerjakan pada trimester pertama, sedangkan appendiktomi adalah prosedur pembedahan yang paling sering dikerjakan pada trimester selanjutnya. Pembedahan mayor adakalanya harus dikerjakan bila terjadi keadaan yang mengancam nyawa ibu, seperti bedah kardiak atau bedah saraf. Pembedahan non obstetrik selama periode kehamilan dapat memberi kontribusi terjadinya morbiditas dan mortalitas perinatal, akibat perjalanan penyakit dasarnya sendiri atau efek terapi, kemungkinan paparan anestetika yang teratogenik, gangguan perfusi uteroplasenta dan atau oksigenasi janin, serta adanya risiko terjadi abortus atau persalinan prematur. Penatalaksanaan anestesi optimal memerlukan pemahaman ahli anestesi mengenai perubahan fisiologi maternal, pertimbangan terhadap janin akibat pembedahan dan anestesi, serta upaya mempertahankan perfusi uteroplasenta dan oksigenasi maternal-janin..$^{2-5}$ Hidrosefalus adalah pembesaran ventrikulus otak sebagai akibat peningkatan jumlah cairan serebrospinal (CSS) yang disebabkan oleh ketidakseimbangan antara produksi, sirkulasi dan absorbsinya. Kondisi ini juga bisa disebut sebagai gangguan hidrodinamik. ${ }^{6}$ External ventricular drainage (EVD) paling sering dan paling penting sebagai prosedur penyelamat jiwa pada penurunan kesadaran akibat adanya kenaikan tekanan intrakranial. Dengan pemakaian alat ini maka tekanan intrakranial yang tinggi dapat menurun dengan menyeimbangkan aliran cairan serebrospinal. ${ }^{6}$

\section{Kasus}

\section{Anamnesis}

Seorang pasien perempuan berusia 35 tahun masuk di ruang instalasi gawat darurat (IGD) dengan penurunan kesadaran sejak 5 jam sebelum masuk rumah sakit. Pasien saat datang juga dalam kondisi hamil dengan usia kehamilan 32-33 minggu, riwayat trauma sebelumnya disangkal, riwayat demam disangkal, hipertensi sebelumnya disangkal, pasien selama ini kontrol ke dokter spesialis kandungan karena ini merupakan anak pertama dari 6 tahun pernikahannya, ada mual dan muntah.

Pemeriksaan Penunjang

Dari pemeriksaan penunjang didapatkan hasil

\begin{tabular}{llll}
\hline Hb: Hemoglobin & $11,8 \mathrm{~g} / \mathrm{dL}$ & Na: Natrium & $142 \mathrm{mEq} / \mathrm{L}$ \\
Ht: Hematokrit & $32,0 \%$ & K: Kalium & $3,8 \mathrm{mEq} / \mathrm{L}$ \\
L: Leukosit & $18.120 / \mu \mathrm{L}$ & Cl: Chlorida & $105 \mathrm{mEq} / \mathrm{L}$ \\
T: Thrombosit & $269.000 / \mu \mathrm{L}$ & Ur: Ureum & $48 \mathrm{mg} / \mathrm{dL}$ \\
PT: Protrombin Time & $12,5(13,8)$ detik & Cr: Creatinin & $1,2 \mathrm{mg} / \mathrm{dL}$ \\
APTT: Activated Partial & $33,5(33,6)$ detik & KGD : & $109 \mathrm{mg} / \mathrm{dL}$ \\
Thromboplastin Time & & Kadar Gula Darah Puasa & \\
TT: Thrombin Time & $13,5(18,7)$ detik & Albumin & $3.6 \mathrm{~g} / \mathrm{dL}$ \\
$\begin{array}{l}\text { INR : International Nor- } \\
\text { malized Ratio }\end{array}$ & 1,27 detik & & \\
\hline
\end{tabular}



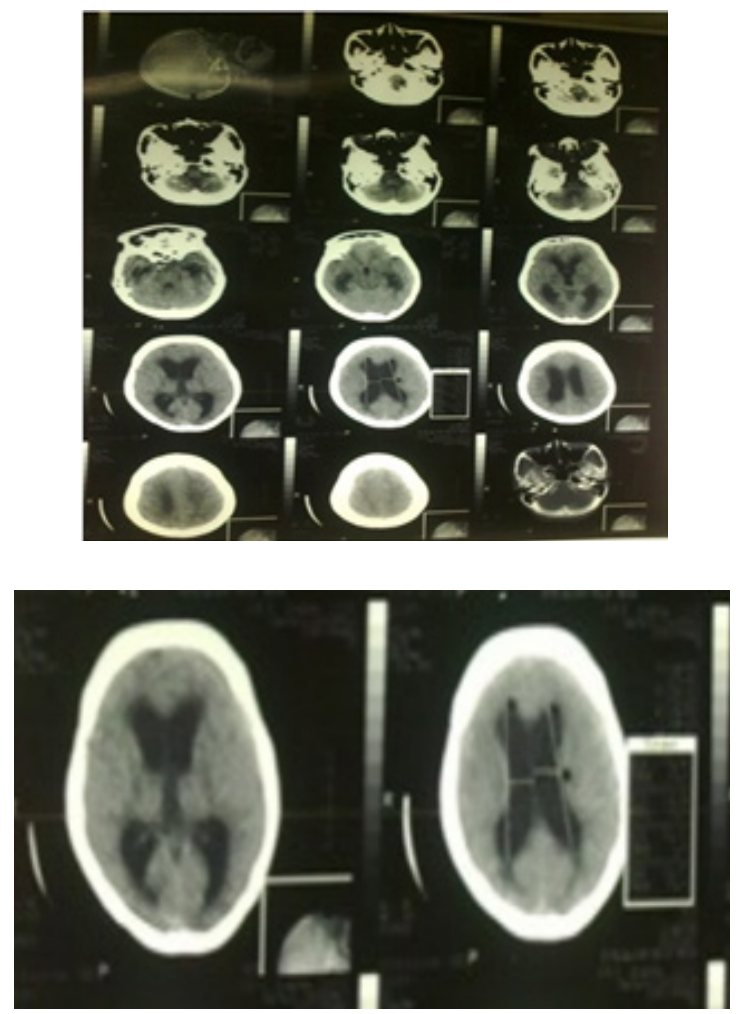

Gambar 2. Gambaran CT-Scan: Tampak Pelebaran pada Kedua Ventrikel, Kesan Hidrocefalus

\section{Pemeriksaan Fisik}

Dari Sensorium: GCS E2E3M5. Kepala: Mata: Reflek cahaya dijumpai pupil isokor bulat $3 \mathrm{~mm}$. Mulut: Buka mulut 3 jari, gigi utuh. Leher: Fleksi ekstensi leher baik, kelainan lainnya tidak ada. Thoraks: Jantung: Denyut jantung 78x/menit, reguler, suara jantung dijumpai tanpa murmur dan suara tambahan, tekanan darah 110/70
mmHg. Paru: Nafas spontan frekuensi napas 16x/ menit, suara pernafasan vesikuler tanpa ada suara tambahan atau lateralisasi, batas jantung dalam batas normal. Abdomen: pembesaran dijumpai, bising usus dijumpai. Urogenitalia: Terpasang kateter urine. Ekstremitas tidak deformitas, hangat, temperatur aksila $36,7^{\circ} \mathrm{C}$, capilary refill test kurang dari 2 detik. Pemeriksaan Obstetri: tinggi fundus uteri 2 jari diatas umbilikus, dan pemeriksaan ultrasonografi menunjukkan denyut jantung janin 140x/menit.

\section{Pengelolaan Anestesi}

Operasi dilakukan dengan pemberian fentanyl 25 mcg dan dilanjutkan dengan tindakan anestesi scalp block combined occipital block dengan ropivakain $0,375 \%$ (diencerkan menjadi $10 \mathrm{cc}$ ), pasien selama operasi juga dilakukan pemasangan kardiotokografi untuk menilai denyut jantung janin selama operasi. Setelah pembedahan pasien dipindahkan ke ruang pemulihan selama 2 jam dan selanjutnya dirawat diruangan HCU bedah saraf. Pasien dirawat selama lebih kurang 1 minggu diruangan bedah saraf dan evaluasi didapatkan kesadaran composmentis dengan hemodinamik yang relatif stabil, serta dipersiapkan untuk dilakukan tindakan seksio sesarea karena mempertimbangkan pematangan dari paru janin.

\section{Pengelolaan Pascabedah}

Pengelolaan pascabedah pasien dilakukan di ruang HCU bedah saraf. Suplementasi oksigen diberikan $3 \mathrm{~L} /$ menit menggunakan nasal kanul.

Tabel 1. Hemodinamik Pasien Intraoperatif

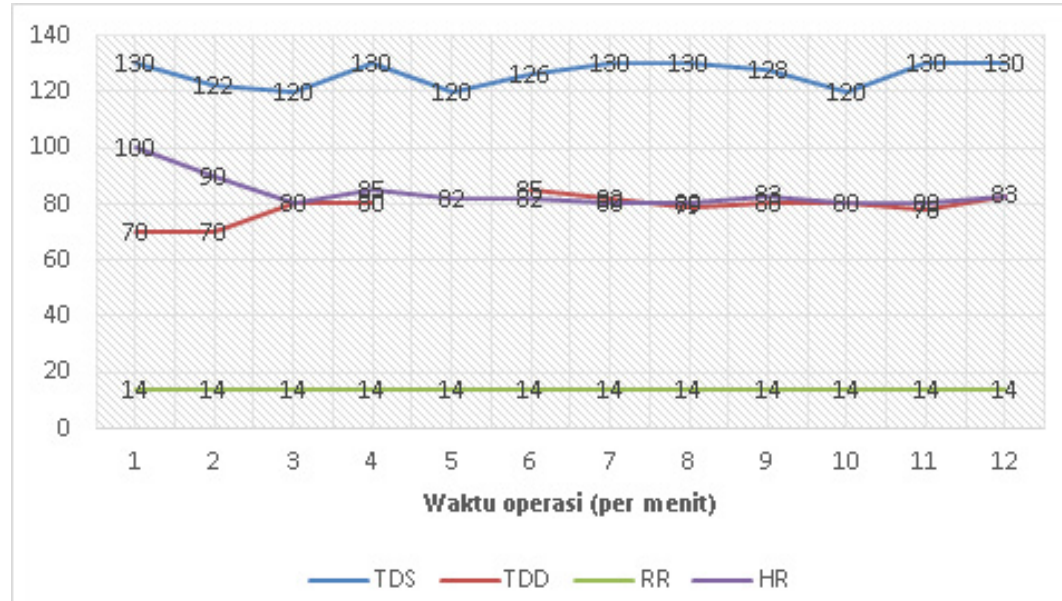




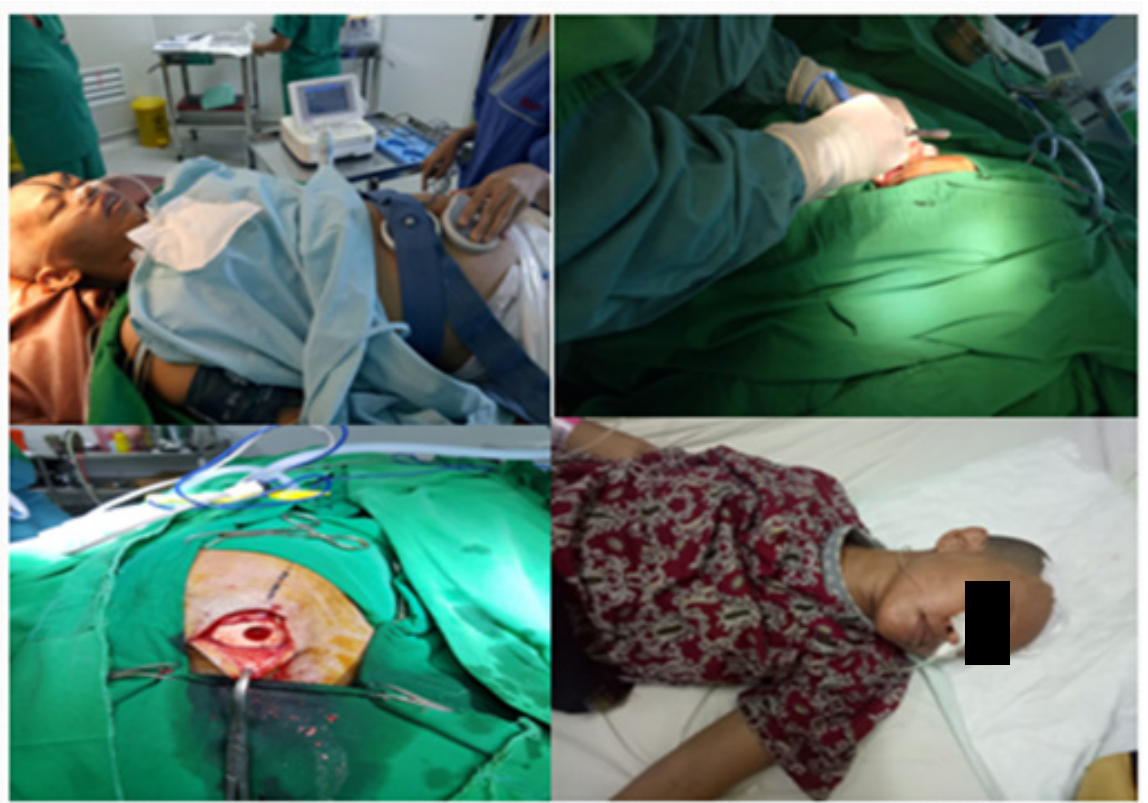

Gambar 2.2. : (1) kondisi Pasien sebelum dioperasi, (2). Awal mulainya Operasi

Terapi yang diberikan adalah ceftriaxon $2 \mathrm{gr} / 24$ jam, analgetik infus parasetamol $1 \mathrm{gr} / 8 \mathrm{jam}$ $\mathrm{IV}$, inj ketorolac $30 \mathrm{mg} / 8$ jam intravena, dan ranitidine $50 \mathrm{mg} / 12$ jam iv. Pasien juga dipasang nasogastric tube (NGT). Dokter obs-gyn tetap memantau perkembangan dan tanda-tanda vital janin dengan ultrasonografi doppler secara berkala. Pada hari ke-1 dan ke-2, tanda-tanda vital pasien dan bayi dinilai stabil dan tidak mengeluhkan nyeri pada lokasi operasi. Pada hari ketiga kondisi hemodinamik stabil, mulai tampak perbaikan status neurologis, pasien dipindahkan ke ruangan.

\section{Pembahasan}

Pada pembedahan non obstetri pada pasien hamil, obat-obat anestesi yang digunakan harus dipertimbangkan karena obat anestesi pada umumnya mempengaruhi sistim kardiorespirasi sehingga dapat membahayakan kondisi ibu maupun janinnya sendiri, namun pada saat usaha menyelamatkan nyawa, ibu terkadang harus lebih diutamakan. Ahli anestesi dalam melakukan tindakan anestesi pada ibu hamil harus mempertimbangkan 3 hal pokok; keselamatan ibu, keselamatan janin dan keselamatan uterus. Pasien pada kasus ini datang dengan penurunan kesadaran karena hidrosefalus dengan kehamilan
32-33 minggu, dan ini merupakan kehamilan pertama sejak 6 tahun pernikahannya. Pada ibu hamil harus diingat terjadi perubahan fisiologis. Obat anestesi dapat berefek pada janin dengan 2 cara yaitu efek langsung obat melalui transfer plasenta yang lebih menonjol pada anestesi umum dan efek tidak langsung yaitu kondisi yang dihasilkan obat dalam interaksinya dengan kondisi/perubahan biokimia ibu diantaranya yaitu loading cairan intravena, penggunaan vaso presor, posisi uterine displacement, dan tingkat blokade simpatis, fraksi inspirasi oksigen, insisi kulit, dan interval uterine incision to delivery dalam penggunaan sedatif sebelumnya., $3,7,9$ Pencegahan terhadap hipoksia dan hipotensi merupakan keharusan walaupun periode hipoksemia yang pendek masih bisa ditoleransi. Hipoksemia maternal yang berkepanjangan akan menyebabkan vasokonstriksi sirkulasi uteroplasental yang pada akirnya menurunkan perfusi sehingga menyebabkan hipoksemia, asidosis dan kematian janin. Doktrin MonroeKellie menyatakan bahwa volume total dalam kranium selalu tetap karena tulang tengkorak tidak elastis sehingga tidak bisa mengembang jika ada penambahan volume. Pada kondisi normal, volume intrakranial terdiri dari $80 \%$ jaringan otak, $10 \%$ CSS, dan $10 \%$ darah. Peningkatan volume dari salah satu komponen ini, atau 
adanya tambahan komponen patologis (misalnya hematom intrakranial), akan menimbulkan kompensasi melalui penurunan volume dari komponen lainnya untuk mempertahankan tekanan. Pada pasien ini terjadi peningkatan volume CSS sehingga terjadi peningkatan intracranial, sehingga harus segera ditangani, dan dilakukan tindakan external ventrikular drainage (EVD) sebagai tindakan emergensi.6,7,11

Jika operasi harus dilakukan selama kehamilan, waktu operasi harus mempertimbangkan resiko ibu, janin dan urgensi dari operasi. Operasi elektif sebaiknya tidak dilakukan selama kehamilan. Dari sisi janin, trimester kedua adalah waktu yang optimal untuk operasi. Secara teoritis, resiko teratogenik meningkat selama periode organogenesis pada trimester pertama dan resiko persalinan prematur tinggi selama trimester ketiga. Risiko terhadap ibu lebih besar selama trimester ketiga yang dipengaruhi perubahan fisiologis kehamilan. Risiko terjadinya abortus selama trimester pertama sekitar $12 \%$ dan resiko ini berkurang pada trimester kedua menjadi sekitar $0 \%-5,6 \%$. Risiko persalinan prematur selama trimester kedua adalah 5\%. Pada pasien ini tindakan pembedahan tergolong urgent karena telah terjadi defisit neurologis akut pada pasien., 3.5 Seorang ahli anestesi mutlak harus memahami perubahan fisiologis kehamilan, implikasi yang ditimbulkan, serta risiko anestesi terhadap kehamilan. Tehnik anestesi dipilih berdasarkan indikasi maternal dan disesuaikan dengan jenis pembedahannya. Tidak ada penelitian yang menyatakan bahwa outcome janin lebih baik dengan suatu tehnik anestesi tertentu. Jika memungkinkan dipilih tehnik anestesi lokal atau regional (kecuali blok paraservikal), mengurangi kemungkinan paparan obat yang berefek teratogenik dan risiko komplikasi respirasi maternal dapat diminimalkan. ${ }^{3,4,8}$ Pemantauan intraoperatif meliputi pengukuran tekanan darah noninvasif maupun invasif, EKG, pulse oksimetri, kapnografi, suhu, dan penggunaan stimulator saraf. Penting untuk memonitor tanda foetal distress, dan jika memungkinkan, dilakukan pemantauan denyut jantung janin dan aktivitas uterine selama pembedahan berlangsung. Pemantauan denyut jantung janin digunakan untuk menentukan oksigenasi serebral yang adekuat pada janin. Penurunan denyut jantung mencerminkan oksigenasi serebral janin yang tidak adekuat. ${ }^{3,13,14}$

Penyuntikan obat anestesi lokal pada scalp block dapat dilakukan pada beberapa titik. Untuk blok pada saraf supra orbita dan sebagian daerah frontal dapat diberikan suntikan di supratrochlear nerve dan supraorbital nerve, untuk daerah antara frontal dan temporal dapat disuntikkan di daerah zigomaticotemporal nerve, untuk daerah temporal dapat disuntikkan obat anestesi lokal didaerah aurikulotemporal nerve, dan untuk daerah occipital dan sebagian lobus temporal bagian ke posteriornya dapat disuntikkan obat didaerah leser occipital dan greater occpital nerve. ${ }^{13}$ Obat anestesi lokal yang dapat diberikan adalah Ropivacaine dengan konsentrasi $0,2 \%$ sampai $1 \%$. Pada pasien obstetrik perlu diperhatikan adanya toksisitas sistemik pada pemberian obat anestesi lokal terutama obat yang memiliki onset lambat. Disamping itu yang dibutuhkan hanya sensori blok. Sehingga dapat diberikan dengan konsentrasi $0,375 \%$ pada setiap daerah yang akan diblok sebanyak 2-3 cc.

EVD atau external ventricular drainage dipasangkan melalui burr hole frontal atau posterior parietal, yang nantinya akan diletakkan EVD. EVD diposisikan dekat ventrikel otak yang memiliki CSF berlebih, setelah dilakukan pemasangan, reservoir diposisikan di subkutan lalu luka burr hole ditutup. Pasien yang dilakukan pemasangan EVD tidak memliki komplikasi setelah follow-up 6 bulan, dan EVD dinyatakan aman dan bermanfaat pada pasien dengan rencana pemasangan EVD yang lebih lama. ${ }^{15}$ Pasien yang dipasangi EVD juga mengalami penurunan skor Glasgow Comma Scale (GCS) dan Glasgow Outcome Scale (GOS) sampai ke skor 3. ${ }^{16}$

\section{Simpulan}

Wanita hamil usia 35 tahun dengan penurunan kesadaran dari foto CT-Scan ditemukan adanya pelebaran ventrikel sehingga didiagnosis hidrosefalus. Dari diagnosa ini maka dilakukan tindakan external ventricular drainage (EVD). 
Pasien kami kelola berdasarkan pertimbangan tentang kondisi ibu, janin dan uterusnya. Pada pasien ini kami memilih tindakan dengan cara regional anestesi dengan blok saraf perifer karena efek obat yang menimal kepada janin dan uterus, serta dapat memblokade nyeri sampai VAS terendah. Tindakan scalp block dan occipital nerve block menjadi pilihan pada operasi ini. Pembiusan regional ini juga dapat digunakan sebagai penanganan nyeri post operasi, sehingga meningkatkan kenyamanan bagi pasien.

\section{Daftar Pustaka}

1. Upadya M, Saneesh PJ. Anaesthesia for nonobstetric surgery during pregnancy. Indian $\mathrm{J}$ Anaesth 2016;60:234-41.

2. Goma HM. Management of brain tumor in pregnancy-an anesthesia window. Dalam: Lichtor T, editor. Clinical Management and Evolving Novel Therapeutic Strategies for Patients with Brain Tumors. Egypt: Intech; 2013, 555-68.

3. Jain D, Kohli A, Gupta L, Bhadoria P, Anand R. Anaesthesia for in vitro fertilisation. Indian J Anaesth. 2009; 53(4): 408-13.

4. Morgan GE, Mikhail MS, Murray MJ. Anesthesia for neurosurgery. Dalam: Morgan GE, Mikhail MS, Murray MJ, editor. Clinical Anesthesiology. Edisi ke-4. United States of America: the McGraw-Hill Companies. 2006, 631-46.

5. Wang LP, Paech MJ. Neuroanesthesia for the pregnant woman. Anesth Analg. 2008;107:193-200.

6. Muralidharan R. External ventricular drains: management and complications. Surgical Neurology International 2015; 6: 271-74.

7. Mhuireachtaigh RN, O'Gorman DA. Anesthesia in pregnant patients for nonobstetric surgery. Journal of Clinical Anesthesia 2006;18:60-66.
8. Burnand C, Sebastian J. Survey of anaesthesia for awake craniotomy. J Neurosurg Anesthesiol 2012; 24: 249.

9. Abdou SA, Shehab HA, Samir EM, Eissa EM. Preliminary evaluation of ketofol-based sedation for awake craniotomy procedures. Egyptian Journal of Anaesthesia. 2010; 26: 293-97.

10. Weiner CP, Eisenach JC. Uteroplacental blood flow. Dalam: Chesnut DH, editor. Obstetric Anesthesia Principles and Practice. Third edition. Philadelphia: Elsevier Mosby; 2004, 37-46

11. Birnbach DJ, Browne IM. Anesthesia for obstetrics. Dalam: Miller RD, editor. Miller's Anesthesia. Edisi ke-7. Philadelphia: Churchill Livingstone Elsevier; 2010, 220336.

12. Wrede KH, Stieglitz LH, Fiferna A. Patient acceptance of awake craniotomy. Clin Neurol Neurosurg 2011; 113: 880-84.

13. Yordanova YN, Moritz-Gasser S, Duffau H. Awake surgery for WHO grade II gliomas within 'noneloquent' areas in the left dominant hemisphere: toward a 'supratotal' resection. J Neurosurg 2011; 115: 232-39.

14. Brydges G, Atkinson R, Perry MJ, Hurst D, Laqua T, Wiemers J. Awake craniotomy: a practice overview. AANA J 2012; 80: 61-8.

15. Chan KH, Mann KS. Prolonged therapeutic external ventricular drainage: a prospective study. Neurosurgery, 1998; 23(4): 436-38.

16. Chen CC, Liu CL, Tung YN, Lee HC, Chuang $\mathrm{HC}$, Lin SZ, et al. Endoscopic surgery for intraventricular hemorrhage (IVH) caused by thalamic hemorrhage: comparisons of endoscopic surgery and external ventricular drainage (EVD) surgery. World Neurosurgery, 75(2), 264-268. 